\title{
Body mass index, waist circumference, and the clustering of cardiometabolic risk factors in early childhood
}

\author{
Laura N. Anderson, Gerald Lebovic, Jill Hamilton, Anthony J. \\ Hanley, Brian W. McCrindle, Jonathon L. Maguire, Patricia C. \\ Parkin, Catherine S. Birken on behalf of the TARGet Kids \\ Collaboration
}

\author{
Version Post-print/accepted manuscript \\ Citation Anderson, L. N., Lebovic, G., Hamilton, J., Hanley, A. J., McCrindle, B. \\ (published version) W., Maguire, J. L., Parkin, P. C., Birken, C. S. and TARGet Kids \\ Collaboration (2016), Body Mass Index, Waist Circumference, and the \\ Clustering of Cardiometabolic Risk Factors in Early Childhood. \\ Paediatr Perinat Epidemiol, 30: 160-170. doi:10.1111/ppe.12268
}

Publisher's Statement This is the peer reviewed version of the following article: Anderson, L. N., Lebovic, G., Hamilton, J., Hanley, A. J., McCrindle, B. W., Maguire, J. L., Parkin, P. C., Birken, C. S. and TARGet Kids Collaboration (2016), Body Mass Index, Waist Circumference, and the Clustering of Cardiometabolic Risk Factors in Early Childhood. Paediatr Perinat Epidemiol, 30: 160170, which has been published in final form at doi:10.1111/ppe.12268. This article may be used for noncommercial purposes in accordance with Wiley Terms and Conditions for Self-Archiving.

\section{How to cite TSpace items}

Always cite the published version, so the author(s) will receive recognition through services that track citation counts, e.g. Scopus. If you need to cite the page number of the author manuscript from TSpace because you cannot access the published version, then cite the TSpace version in addition to the published version using the permanent URI (handle) found on the record page.

This article was made openly accessible by $U$ of $T$ Faculty.

Please tell us how this access benefits you. Your story matters. 
Body mass index, waist circumference, and the clustering of cardiometabolic risk factors in early childhood

Laura N. Anderson ${ }^{\mathrm{a}, \mathrm{b}}$, Gerald Lebovic ${ }^{\mathrm{c}, \mathrm{d}}$, Jill Hamilton ${ }^{\mathrm{e}, \mathrm{f}, \mathrm{g}}$, Anthony J. Hanley ${ }^{\mathrm{g}}$, Brian W. McCrindle ${ }^{\mathrm{b}, \mathrm{f}}$, Jonathon L. Maguire ${ }^{\mathrm{c}, \mathrm{d}, \mathrm{f}, \mathrm{g}}$, Patricia C. Parkin ${ }^{\mathrm{b}, \mathrm{d}, \mathrm{f,h}}$, Catherine S. Birken ${ }^{\mathrm{b}, \mathrm{d}, \mathrm{f,h}}$ on behalf of the TARGet Kids Collaboration*.

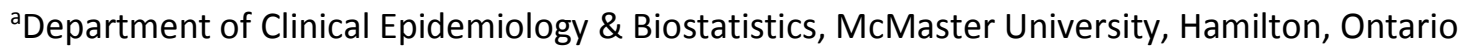

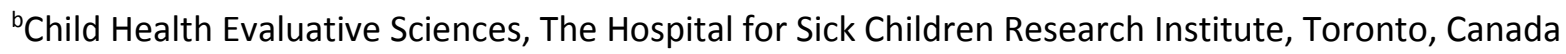
'The Applied Health Research Centre of the Li Ka Shing Knowledge Institute of St. Michael's Hospital, Toronto, Ontario

dinstitute for Health Policy, Management and Evaluation, University of Toronto, Toronto, Ontario eDivision of Endocrinology, The Hospital for Sick Children, Toronto, Ontario

fDepartment of Pediatrics, Faculty of Medicine, University of Toronto, Toronto, Ontario gDepartment of Nutritional Sciences, University of Toronto, Toronto, Ontario hDivision of Pediatric Medicine and the Pediatric Outcomes Research Team, The Hospital for Sick Children, Toronto, Ontario;

Short Title: Cardiometabolic risk in early childhood

Correspondence to: Dr. Catherine Birken, The Hospital for Sick Children, Division of Paediatric Medicine, 686 Bay Street, Rm. $10^{\text {th }}$ floor, Peter Gilgan Centre for Research and Learning, Toronto, Ontario, M5G 0A4. E-mail: catherine.birken@sickkids.ca 


\section{Abstract (250 words)}

Background: Obesity has its origins in early childhood, however, there is limited evidence of the association between anthropometric indicators and cardiometabolic risk factors in young children. Our aim was to evaluate the associations between body mass index (BMI) and waist circumference (WC) in relation to cardiometabolic risk factors, and to explore the clustering of these factors.

Methods: A cross-sectional study was conducted in children aged 1-5 years through TARGet Kids! ( $n=2917)$. Logistic regression was used to evaluate associations between BMI and WC $z$-scores and individual traditional and possible non-traditional cardiometabolic risk factors. The underlying clustering of these measures was evaluated using principal components analysis (PCA).

Results: Child obesity (BMI z-score $>2$ ) was associated with high $\left(>90^{\text {th }}\right.$ percentile) leptin $(\mathrm{OR}=8.15$; 95\%Cl:4.56-14.58) and insulin ( $\mathrm{OR}=1.76 ; 95 \% \mathrm{Cl}: 1.05-2.94)$. WC $\mathrm{z}$-score $>1$ was associated with high insulin (OR=1.59; 95\%Cl: 1.11-2.28), leptin (OR=5.48; 95\%Cl:3.48-8.63) and 25-hydroxyvitamin D $<75 \mathrm{nmol} / \mathrm{L}(\mathrm{OR}=1.39 ; 95 \% \mathrm{Cl}: 1.08-1.79) . \mathrm{BMI}$ and $\mathrm{WC}$ were not associated with other traditional cardiometabolic risk factors, including non-HDL cholesterol, and glucose. Among children 3-5 years ( $n=1035)$ the PCA of traditional risk factors identified 3 components: adiposity/blood pressure, metabolic, and lipids. The inclusion of non-traditional risk factors identified 3 additional components, but contributed minimally to the total variation explained.

Conclusions: Anthropometric indicators are associated with selected cardiometabolic risk factors in early childhood, although the clustering of risk factors suggests that adiposity is only one distinct component of cardiometabolic risk. The measurement of other risk factors beyond BMI and WC may be important in defining cardiometabolic risk in early childhood. 


\section{Introduction}

Childhood obesity and cardiometabolic dysfunction have been identified as important determinants of both child and adult health. ${ }^{1}$ Being overweight in early childhood is strongly associated with obesity in adolescence ${ }^{2}$ and adulthood. ${ }^{3}$ Childhood overweight and obesity has been associated with cardiometabolic risk factors in late childhood or adolescence, ${ }^{4,5}$ yet there is a paucity of literature in preschoolers. In older children, body mass index $(\mathrm{BMI})^{6-9}$ or waist circumference $(\mathrm{WC})^{7,9}$ has been associated with a number of individual cardiometabolic risk factors. It is possible that these associations may vary in early childhood due to different risk factor exposures and hormone profiles.

In adults, the clustering of risk factors for cardiovascular disease and diabetes is known as the Metabolic Syndrome (MetS) and is defined as the presence of at least 3 of the following: elevated blood pressure (BP), central obesity, elevated triglycerides, elevated glucose and lower high density (HDL) cholesterol. ${ }^{10} \mathrm{WC}$ is used instead of $\mathrm{BMI}$ in adults as it better reflects central obesity and the volume of visceral adipose tissue, which is more metabolically detrimental than subcutaneous adipose tissue. ${ }^{11}$ Despite criticisms of the MetS, the standard definition has furthered the field of research and is useful for predicting disease risk in populations. ${ }^{12,13}$ There is no consensus on whether MetS exists in young children or how cardiometabolic risk should be defined. ${ }^{14,15}$ Applying the adult definition of MetS in early adolescence does not reliably predict presence of the MetS in young adults ${ }^{16}$ yet there is some evidence that continuous measures of cardiometabolic risk factors track from older childhood to early adulthood. ${ }^{16}$ Determination of the interrelatedness or clustering of cardiometabolic risk factors and anthropometric measures in early childhood may yield important insights on the underlying etiology of cardiometabolic conditions. The clustering of cardiometabolic risk factors has been evaluated using principal components analysis (PCA) in older children or adolescents ${ }^{9,17-19}$ and recently in newborns, ${ }^{20}$ but not in early childhood. PCA is a variable reduction procedure that reduces interrelated variables into a discrete set of underlying components. ${ }^{21}$ 
There is emerging evidence in adolescents and adults that additional possible 'non-traditional risk factors' including subclinical inflammation, adipocyte dysfunction and fatty liver disease (reflected by biomarkers such as leptin, adiponectin, 25-hydroxyvitamin D (25(OH)D), C-reactive protein (CRP), alanine aminotransferase (ALT), and apolipoprotein (Apo)-A1 and Apo-B) may be important aspects of cardiometabolic risk. ${ }^{9,22}$ In older children, leptin, adiponectin, CRP, Apo-A1 and Apo-B have been associated with the metabolic syndrome, and these possible non-traditional risk factors correlate with traditional risk factors to explain the core traits underlying cardiovascular risk profiles. ${ }^{9}$ Both $\mathrm{ALT}^{23}$ and $25(\mathrm{OH}) \mathrm{D}^{12,} 22$ have been associated with cardiometabolic risk factors in adults although their role as possible non-traditional risk factors in childhood is not yet well understood. To our knowledge, no studies have used PCA to evaluate the components that underlie the clustering of anthropometric measures and both traditional and non-traditional cardiometabolic risk factors in early childhood. Since cardiovascular disease outcomes are rare in childhood, understanding the interrelatedness of cardiometabolic risk factors in early childhood may be useful in defining a summary measure of cardiometabolic risk which could be used as an intermediate outcome in epidemiological studies and clinical trials. The development of valid and reliable Intermediate outcome measures that can be applied in childhood and are predictive of adult cardiovascular disease and diabetes are important to identify opportunities for intervention.

Our primary objective was to evaluate if anthropometric measures of adiposity, BMI and WC, were associated with individual traditional cardiometabolic factors (HDL, non-HDL, triglycerides, glucose, insulin) and possible non-traditional factors $(25(\mathrm{OH}) \mathrm{D}, \mathrm{ALT}, \mathrm{Apo}-\mathrm{A}, \mathrm{Apo}-\mathrm{B}$, leptin, adiponectin, CRP). The secondary objective was to use PCA for the anthropometric measures and cardiometabolic risk factors to identify the cluster of underlying components in early childhood.

\section{Methods}

Study Design 
A cross sectional study was conducted of children between 1 and 5 years of age attending scheduled well-child visits through TARGet Kids!. TARGet Kids! is a primary care practice based research network (www.targetkids.ca) and has been described previously. ${ }^{24}$ Children were recruited from 9 pediatric or family practice primary care clinics in Toronto, Canada between 2008 and 2012. Children with severe developmental delay or chronic illness (except for asthma) were excluded. Consent was obtained from parents of all participating children and ethical approval was obtained from the Research Ethics Board at The Hospital for Sick Children and St. Michael's Hospital (www.clinicaltrials.gov; NCT01869530).

\section{Anthropometric Measures}

Height and weight were measured by trained research staff. Weight was measured using a precision digital scale (SECA, Germany), standing height was measured using a stadiometer (SECA), and length for children under 2 years old was measured using a length board, using standardized methods. BMI was calculated as the weight in kilograms divided by the height (or length) in meters squared. BMI z-scores were defined using the World Health Organization (WHO) growth standards. ${ }^{25}$ The WHO growth standards were selected as they are meant to reflect optimal growth in children and are recommended for use in this age group in Canada. ${ }^{26}$ 'Overweight or obese' was defined as a BMI z-score greater than 1 and 'obese' was defined as a BMI z-score greater than $2 .{ }^{26}$

In the absence of established WC standards for young children, standardized WC was calculated within our study population by age (in years) and sex. Within each age and sex group a mean and standard deviation were computed for WC and each subject's z-score was computed using these means and standard deviations. Calculated WC z-scores were very similar to those calculated in a large US sample of children 2 years and older in the National Health and Nutrition Examination Survey (NHANES). ${ }^{27}$

\section{Cardiometabolic Measures}


Non-fasting blood samples $(4-7 \mathrm{ml})$ were collected in the primary care office by experienced pediatric phlebotomists at the time of the child's scheduled clinic visit (between 9am to 6pm weekdays). The collection of fasting blood samples in preschool children may not be feasible, and is not likely to be implemented in clinical practice by parents or physicians. The time since last oral intake was recorded. Specimens were transported by research assistants to Mount Sinai Services Laboratory (http://www.mountsinaiservices.com).

All laboratory analysis were performed by the Mount Sinai Services Laboratory using standard procedures as follows: Glucose was measured using enzymatic reference method with hexokinase; Adiponectin was measured using Radioimmunoassay, Linco Research Inc.; Leptin was measured using ELISA, Linco Research Inc.; C-reactive protein was measured using article-enhanced immunoturbidometric assay, Roche Modular; Lipids (total cholesterol, triglycerides, HDL, and non-HDL) were measured using enzymatic colourmetric on the Roche Modular platform; Insulin was measured using Electrochemiluminescence Immunoassay "ECLIA"; 25-Hydroxyvitamin D was measured using chemiluminescence immunoassay (Diasorin LIAISON); and Apo-A1 and Apo-B were measured using the immunoturbidimetric assay on the Roche CobasIntergra 400 platform. All data were uploaded to the central MediData Rave platform (MediData Solutions, New York) housed at the Applied Health Research Centre of the Li Ka Shing Knowledge Institute, St. Michael's Hospital, Toronto.

Traditional blood cardiometabolic measures included total cholesterol, HDL cholesterol, nonHDL cholesterol (total cholesterol minus HDL), triglycerides, glucose, insulin; possible non-traditional cardiometabolic measures included 25(OH)D, ALT, leptin, adiponectin, Apo-A1 and Apo-B, and CRP. ${ }^{28}$ Cut-points for high risk were determined based on existing standards for children ${ }^{28}$ or using the 90th percentile in the absence of defined criteria. Systolic and diastolic BP was measured only in children age 3 and older. ${ }^{29} \mathrm{BP}$ was assessed by trained research assistants using mercury sphygmomanometers at 5 clinics and automated oscillatory devices at 4 clinics with the appropriate size child BP cuff at the time of 
the child's scheduled clinic visit (between 9am to 6pm) according to the guidelines of the National High Blood Pressure Education Program (NHBPEP) ${ }^{29}$ and using the NHANES cut-offs..$^{28,29}$ Data on other covariates, including age, sex, maternal education and maternal ethnicity, were collected using a parentcompleted, standardized questionnaire.

\section{Statistical Analysis}

Logistic regression was used to evaluate the associations between categories of both BMI zscore and WC $z$-score ( $>1$ versus $\leq 1$; and $>2$ versus $\leq 2$ ), and each cardiometabolic outcome variable using pre-determined cut-point values and to obtain odds ratios (OR) and $95 \%$ confidence intervals. The models with insulin, glucose and triglycerides were adjusted for time since last meal. The primary analyses were all conducted using the dichotomized variables for clinical relevance; supplementary analyses were conducted using continuous measures of both BMI and WC z-scores. Statistical analysis was conducted using SAS statistical software version 9.3 (SAS Institute Inc., Cary, NC, USA) and R version

\subsection{1 (http://www.R-project.org/).}

PCA was performed using varimax orthogonal rotation. ${ }^{21}$ PCA was first conducted for a simple group of variables that included only the components of the metabolic syndrome: WC z-score, HDL, glucose, triglycerides, and systolic blood pressure. Subsequently, a second PCA was conducted with all of the traditional risk factors (including BMI z-score, WC z-scores, non-HDL, HDL, insulin, glucose, systolic and diastolic blood pressure) and a third PCA included both the traditional and possible non-traditional risk factors combined (including all traditional risk factors plus leptin, CRP, ALT, Apo-A1, Apo-B, Adiponectin, and 25(OH)D). For each of the three groups of variables, separate PCA models were created for all ages combined and for only age 3 and older, since BP was only measured for the latter. We used a combination of criteria to determine the number of components to retain, including components with an Eigenvalue $\geq 1$, examination of scree plots for obvious break patterns and ensuring that the retained components achieved a cumulative proportion of variance explained of approximately 
$70 \%$ or greater. Variables with a factor loading of at least 0.4 were considered to load meaningfully on each component. Varimax (orthogonal decomposition) rotated factor patterns and final communality (variance explained) estimates were reported.

\section{Results}

A total of 4691 children between 1 and 5 years of age were recruited from 2008 to 2012. Blood samples were collected on 2917 (53\%) children (Supplementary Figure 1). Children who provided blood were similar with respect to child sex, maternal education and maternal ethnicity as those who did not provide blood (Table 1); the mean age of children with blood was slightly older than children without blood ( $2.91 \pm 1.51$ versus $2.62 \pm 1.53$ years; $p<0.0001)$. The proportion of children categorized as overweight or obese (BMI z-score $>1$ ) was $15.1 \%$ and WC z-score $>1$ was $11.3 \% ; 4.7 \%$ of children were categorized as obese (BMI z-score $>2$ ) and $2.2 \%$ of children had WC z-score $>2$. BMI and WC z-scores (Pearson's $r=0.55 ; p<0.001$ ) and systolic and diastolic BP (Pearson's $r=0.52 ; p<0.001$ ) were moderately correlated.

BMI z-score $>1$ was significantly associated with high leptin (OR=3.91; $95 \% \mathrm{Cl}: 2.57-5.98)$ and low Apo-A (OR=1.47; 95\%Cl:1.07-2.00) (Table 2). BMI z-score >2 was significantly associated with high insulin $(\mathrm{OR}=1.76 ; 95 \% \mathrm{Cl}: 1.05-2.94)$ adjusted for time since last meal, and high leptin (OR=8.15; 95\% $\mathrm{Cl}: 4.56$ 14.58). WC $z$-score $>1$ was significantly associated with high leptin ( $\mathrm{OR}=5.48 ; 95 \% \mathrm{Cl}: 3.48-8.63)$, low serum 25(OH)D (OR=1.39; 95\%Cl:1.08-1.79), low Apo-B (OR=0.28; 95\%Cl:0.09-0.91) and high insulin (OR=1.59; 95\%Cl:1.11-2.28) (Table 3). WC z-score $>2$ was significantly associated with high leptin (OR=10.81; 95\%Cl:4.29-27.23) and high insulin (OR=2.48; 95\%Cl:1.29-4.79). Results were similar for analysis using continuous measures of BMI and WC (data available upon request).

PCA for the simple model among all children identified 3 components: 1) Lipids (including HDL and triglycerides), 2) Metabolic (including only glucose) and 3) Adiposity (including only WC z-score). Among the subset of children age 3 and older with blood pressure, systolic blood pressure loaded with 
WC z-score, but the Lipid and Metabolic components remained distinct. The model with all children explained $85.2 \%$ of the total variance and the model with only children age 3 and older and included blood pressure explained $69.6 \%$. Similarly, the second PCA with all of the traditional cardiometabolic risk factors among all children identified 3 components which explained $68.9 \%$ of the total variance: 1 ) Adiposity (including BMI z-score and WC z-score), 2) Metabolic (including glucose and insulin) and 3) Lipids (non-HDL and HDL cholesterol)(Supplementary Table 1). For the second PCA, among the subset of children at least 3 years of age with BP measurements, 4 components were identified which explained $70.8 \%$ of the total variance: Adiposity, Metabolic and Lipids (consistent with the results from analysis of all children) and an additional component including both systolic and diastolic BP (Supplementary Table 1). Using triglycerides instead of non-HDL cholesterol did not alter the results with triglycerides and HDL loading on the third component (data not shown).

The third PCA that included all traditional and possible non-traditional cardiometabolic factors combined (Table 5) among all children, identified the following distribution of components: 1) Lipids/HDL (HDL and Apo-A and CRP); 2) Lipids/non-HDL (non-HDL cholesterol and Apo-B); 3) Adiposity (WC z-score, BMI z-score and leptin); 4) Metabolic (glucose and insulin); 5) Adiponectin/ALT: and 6) $25(\mathrm{OH}) \mathrm{D} / \mathrm{ALT}$. These 6 components explained $72.7 \%$ of the total variance in the observed variables. The results were similar among the children at least 3 years of age with one additional component identified that included both systolic and diastolic BP and CRP now loaded with adiponectin suggesting an inflammation component (Table 5). These 7 components explained $74.1 \%$ of the total variance. The correlation matrices for all PCA models are provided in supplementary tables 2-7.

\section{Comments}

The main findings of this study suggest that both BMI and WC are associated with only selected traditional and possible non-traditional cardiometabolic risk factors in early childhood; many cardiometabolic risk factors were not significantly associated with measures of anthropometric 
measures. Statistically significant associations that were observed, including positive associations with both insulin and leptin, were in the expected directions. Only the inverse association observed between WC and Apo-B was unexpected; however, there were few children with high Apo-B and the association between BMI and Apo-B was not significant. PCA of all cardiometabolic and anthropometric risk factors combined also revealed that BMI and WC loaded on only one Adiposity factor which was independent of other traditional cardiometabolic risk factors. The simple PCA revealed three distinct underlying components and this was very similar to the model with all traditional risk factors. In the PCA including possible non-traditional factors BMI and WC loaded positively with leptin, but other traditional and nontraditional cardiometabolic risk factors loaded on separate factors. This suggests that there may be more than one underlying construct that contributes to cardiometabolic risk in early childhood and measurement of other factors beyond anthropometric measures may be warranted.

Previous studies of the associations between anthropometric measures and individual cardiometabolic factors have identified several associations in children age 5 and older. ${ }^{4,5}$ For example, BMI, WC, and fat mass at age 9-12 years were significantly associated with many cardiovascular risk factors at age 15-16 years including: high systolic BP, LDL cholesterol, HDL cholesterol, triglycerides and insulin. ${ }^{5}$ Few studies of children less than 6 years of age have evaluated the associations between WC and $\mathrm{BMI}$ and cardiometabolic risk factors with inconsistent results. ${ }^{30,}{ }^{31}$ Although we found that WC was associated with more measures of cardiometabolic risk than BMI, previously WC and fat mass were not found to be better predictors of cardiovascular risk factors than BMI. ${ }^{5}$ Our study identified fewer significant associations than previous studies in children; this may be due to the young age of the children, where cardiometabolic risk is less established.

Our PCA of 8 traditional risk factors, including BP, identified 4 underlying latent components, which collectively explained $70.8 \%$ of the variance. The Adiposity component explained the greatest portion of the total variance (22.8\%), although the Blood Pressure, Metabolic and Lipid components also 
contributed substantially, with each contributing $18.12 \%, 16.84 \%$ and $12.96 \%$ to the total variance, respectively. There were no variables that loaded on more than one principal component and this may indicate distinct underlying constructs with unique pathologies. These results were similar to a simple model that included only 5 traditional risk factors, to eliminate highly correlated variables. The simple model, including systolic BP, identified three factors Lipid, Metabolic and a combined Adiposity/BP factor and this simple model explained almost $70 \%$ of the total variance. Few studies have evaluated the overall clustering of both anthropometrics and cardiometabolic risk factors and none have included both traditional and non-traditional in young children.

Consistent with our findings, PCA of 11 cardiometabolic risk factors among 442 newborns, measured at birth, revealed 5 principal components defined as anthropometry/insulin, HDL-C/Apo-A1, triglycerides, blood pressure, and glycemia. ${ }^{20}$ In a study of non-traditional cardiovascular risk factors in a high risk population of a Canadian First Nations population age 10-19 years, five factors were identified: adiposity, lipids/adiponectin, inflammation, blood pressure and glucose tolerance. ${ }^{9}$ Other studies in older children and adolescents have evaluated fewer traditional cardiometabolic risk factors and identified only two components ${ }^{17-19}$; defined in one study as a "metabolic" and an "obesity/blood pressure" component. ${ }^{18}$ Our findings are not entirely consistent with the adult studies that have generally identified that insulin loads on more than one factor along with measures of adiposity, glucose and lipids and may or may not include BP as an independent component. ${ }^{32,33}$ This may suggest that there are distinct patterns of cardiometabolic risk in early childhood and not one underlying construct.

The addition of possible non-traditional risk factors contributed minimally to the total amount of variation explained. In our analysis of children 3-5 years of age, the total variation explained increased by only $3 \%$ despite the addition of 7 more non-traditional risk factors and the identification of 3 additional components. Two separate lipid components were identified, the first included both Apo-A and HDL cholesterol, and the second included non-HDL and Apo-B; this is somewhat intuitive as Apo-A is 
a component of HDL and Apo-B is a component of LDL. ALT, which is a marker of fatty liver disorder, was loaded positively with 25(OH)D, whereas adiponectin and CRP inversely loaded on the final component, possibly indicating an inflammation related factor. The direction of these correlations is somewhat unexpected, although a positive correlation between ALT and 25(OH)D has been shown in adolescents. ${ }^{34}$

A major strength of our study is the comprehensive measurement of both traditional and nontraditional cardiometabolic factors in young children; few studies have evaluated children less than 6 years of age. Although blood measures were not available on all children, characteristics of children with and without blood were similar for all characteristics except age. Height, weight, WC, and BP were measured by trained research assistants using standardized equipment and techniques. PCA is a variable reduction tool that is useful for identifying a smaller number of underlying components from correlated variables and, unlike factor analysis, PCA does not incorporate any a priori assumptions about the underlying structure of the data. Identifying a reduced number of variables that define cardiometabolic risk in early childhood may contribute to the definition of a standardized intermediate outcome measure for the characterization of cardiometabolic risk.

Limitations of our study include the standardization of WC using age and sex values within our own cohort and the use of $90^{\text {th }}$ percentiles to define high risk cut points due to the absence of established standards and cut points for several risk factors. Despite a relatively large sample size, due to funding constraints, we did not have complete data on Apo-A, Apo-B and adiponectin. It is also a limitation of our study that non-fasting blood samples were analyzed; however, it is very difficult to obtain fasting samples from young children. In our statistical analysis we adjusted for time since last meal in the models with triglycerides, insulin and glucose. Further, the average lipids and glucose concentrations were very similar in the children who had fasted 6 hours versus those with less than 1 hour fasting; only insulin appeared to be highly dependent on fasting status (data not shown). This is consistent with previous studies, including data from NHANES, which have provided evidence that 
fasting may not be necessary for cholesterol screening in children. ${ }^{35}$ PCA relies on somewhat arbitrary cut points to define the number of factors, and these were evaluated in our study using eigenvalues, scree plots, and an a priori conservative loading threshold of 0.40 . Lastly, in this cross-sectional analysis we cannot establish causation or temporality.

The findings from our study suggest adiposity is only one unique latent factor that contributes to the underlying correlation of cardiometabolic risk factors. Unlike studies of adults and adolescents, insulin resistance does not appear to be a common underlying factor. Further, possible non-traditional risk factors contributed minimally. Given the increasing number of studies focused on cardiometabolic risk in early childhood as an intermediate or 'preclinical' outcome measure, a standard harmonized definition should be adopted. Our study may inform such a definition in early childhood and our results suggest that at minimum measures of adiposity, BP, metabolic and lipid factors are all needed to explain most of the underlying variation in cardiometabolic risk. Future studies should evaluate if a summary score including these measures tracks through childhood and predicts adult cardiovascular disease and diabetes risk. 
Funding: This work was supported by the Canadian Institutes of Health Research (grant number:

119375). Funding agencies had no role in the design and conduct of the study, collection, management, analyses or interpretation of the results of this study or in the preparation, review, or approval of the manuscript.

Acknowledgements: The authors thank all participating families for their time and involvement in TARGet Kids! and are grateful to all practitioners who are currently involved in the TARGet Kids! research network. Steering Committee: Tony Barozzino, Brian Chisamore, Mark Feldman, Moshe Ipp. Research Team: Charmaine Camacho, Diviya Elango, Julie DeGroot, Shanique Edwards, Nadia Kabir, Marina Khovratovich, Tarandeep Malhi, Juela Sejdo, Laurie Thompson, Mandy Tran. Applied Health Research Centre: Magda Melo, Patricia Nguyen. Mount Sinai Services Laboratory: Azar Azad. *TARGet Kids! Collaboration - Scientific Committee: Kawsari Abdullah, Laura N. Anderson, Catherine S. Birken, Cornelia M. Borkhoff, Sarah Carsley, Yang Chen, Matthew D’Ascanio, Mikael Katz-Lavigne, Kanthi Kavikondala, Grace Jieun Lee, Jonathon L. Maguire, Jessica Omand, Patricia C. Parkin, Navindra Persaud, Meta van den Heuvel; Site Investigators: Jillian Baker, Tony Barozzino, Joey Bonifacio, Douglas Campbell, Sohail Cheema, Brian Chisamore, Karoon Danayan, Paul Das, Mary Beth Derocher, Anh Do, Michael Dorey, Sloane Freeman, Keewai Fung, Charlie Guiang, Curtis Handford, Hailey Hatch, Sheila Jacobson, Tara Kiran, Holly Knowles, Bruce Kwok, Sheila Lakhoo, Margarita Lam-Antoniades, Eddy Lau, Fok-Han Leung, Jennifer Loo, Sarah Mahmoud, Rosemary Moodie, Julia Morinis, Sharon Naymark, Patricia Neelands, James Owen, Michael Peer, Marty Perlmutar, Navindra Persaud, Andrew Pinto, Michelle Porepa, Nasreen Ramji, Noor Ramji, Alana Rosenthal, Janet Saunderson, Rahul Saxena, Michael Sgro, Susan Shepherd, Barbara Smiltnieks, Carolyn Taylor, Thea Weisdors, Sheila Wijayasinghe, Peter Wong, Ethel Ying, Elizabeth Young.

Conflict of Interest: The authors declare no conflict of interest. 
Author contributions: CSB and LNA conceived the study design and wrote the first draft of the manuscript. GL analyzed the data. All authors were involved in writing the paper, reviewing the results and had final approval of the submitted manuscript. 


\section{References}

1. Tremblay MS. Major initiatives related to childhood obesity and physical inactivity in Canada: the year in review. Canadian Journal of Public Health. 2012; 103:164-169.

2. Cunningham SA, Kramer MR, Narayan KM. Incidence of childhood obesity in the United States. New England Journal of Medicine. 2014; 370:403-411.

3. Brisbois TD, Farmer AP, McCargar LJ. Early markers of adult obesity: a review. Obesity reviews. 2012; 13:347-367.

4. Freedman DS, Dietz WH, Srinivasan SR, Berenson GS. The relation of overweight to cardiovascular risk factors among children and adolescents: the Bogalusa Heart Study. Pediatrics. 1999; 103:1175-1182.

5. Lawlor DA, Benfield L, Logue J, Tilling K, Howe LD, Fraser A, et al. Association between general and central adiposity in childhood, and change in these, with cardiovascular risk factors in adolescence: prospective cohort study. BMJ. 2010; 341:c6224.

6. Freedman DS, Mei Z, Srinivasan SR, Berenson GS, Dietz WH. Cardiovascular risk factors and excess adiposity among overweight children and adolescents: the Bogalusa Heart Study. The Journal of Pediatrics. 2007; 150:12-17 e12.

7. Katzmarzyk PT, Srinivasan SR, Chen W, Malina RM, Bouchard C, Berenson GS. Body mass index, waist circumference, and clustering of cardiovascular disease risk factors in a biracial sample of children and adolescents. Pediatrics. 2004; 114:e198-205.

8. Cook S, Weitzman M, Auinger P, Nguyen M, Dietz WH. Prevalence of a metabolic syndrome phenotype in adolescents: findings from the third National Health and Nutrition Examination Survey, 1988-1994. Archives of Pediatrics and Adolescent Medicine. 2003; 157:821-827. 
9. Retnakaran R, Zinman B, Connelly PW, Harris SB, Hanley AJ. Nontraditional cardiovascular risk factors in pediatric metabolic syndrome. The Journal of Pediatrics. 2006; 148:176-182.

10. Alberti KG, Eckel RH, Grundy SM, Zimmet PZ, Cleeman JI, Donato KA, et al. Harmonizing the metabolic syndrome: a joint interim statement of the International Diabetes Federation Task Force on Epidemiology and Prevention; National Heart, Lung, and Blood Institute; American Heart Association; World Heart Federation; International Atherosclerosis Society; and International Association for the Study of Obesity. Circulation. 2009; 120:1640-1645.

11. Janssen I, Katzmarzyk PT, Ross R. Waist circumference and not body mass index explains obesity-related health risk. American Journal of Clinical Nutrition. 2004; 79:379-384.

12. Eckel RH, Alberti KG, Grundy SM, Zimmet PZ. The metabolic syndrome. Lancet. 2010; 375:181183.

13. Simmons RK, Alberti KG, Gale EA, Colagiuri S, Tuomilehto J, Qiao Q, et al. The metabolic syndrome: useful concept or clinical tool? Report of a WHO Expert Consultation. Diabtologia. 2010; 53:600-605.

14. Brambilla P, Lissau I, Flodmark CE, Moreno LA, Widhalm K, Wabitsch M, et al. Metabolic riskfactor clustering estimation in children: to draw a line across pediatric metabolic syndrome. International Journal of Obesity. 2007; 31:591-600.

15. Pietrobelli A, Malavolti M, Battistini NC, Fuiano N. Metabolic syndrome: a child is not a small adult. International Journal of Pediatric Obesity. 2008; 3 Suppl 1:67-71.

16. Kelly AS, Steinberger J, Jacobs DR, Hong CP, Moran A, Sinaiko AR. Predicting cardiovascular risk in young adulthood from the metabolic syndrome, its component risk factors, and a cluster score in childhood. International Journal of Pediatric Obesity. 2011; 6:e283-289. 
17. Peterson MD, Liu D, IglayReger HB, Saltarelli WA, Visich PS, Gordon PM. Principal component analysis reveals gender-specific predictors of cardiometabolic risk in 6th graders. Cardiovascular Diabetology. 2012; 11:146.

18. Hobkirk JP, King RF, Gately P, Pemberton P, Smith A, Barth JH, et al. Longitudinal factor analysis reveals a distinct clustering of cardiometabolic improvements during intensive, short-term dietary and exercise intervention in obese children and adolescents. Metabolic Syndrome and Related Disorders. 2012; 10:20-25.

19. Melka MG, Abrahamowicz M, Leonard GT, Perron M, Richer L, Veillette S, et al. Clustering of the metabolic syndrome components in adolescence: role of visceral fat. Plos One. 2013; 8:e82368.

20. Morrison KM, Anand SS, Yusuf S, Atkinson SA, Schulze KM, Rao-Melacini P, et al. Maternal and pregnancy related predictors of cardiometabolic traits in newborns. Plos One. 2013; 8:e55815.

21. Hatcher L. A step-by-step approach to using the SAS system for factor analysis and structural equation modeling. Cary, NC: SAS Institute; 1994.

22. García-Bailo B, Da Costa LA, Arora P, Karmali M, El-Sohemy A, Badawi A. Plasma vitamin D and biomarkers of cardiometabolic disease risk in adult Canadians, 2007-2009. Prevention of Chronic Disease. 2013; 10:E91.

23. Lioudaki E, Ganotakis ES, Mikhailidis DP. Liver enzymes: potential cardiovascular risk markers? Current Pharmaceutical Design. 2011; 17:3632-3643.

24. Carsley S, Borkhoff CM, Maguire JL, Birken CS, Khovratovich M, McCrindle B, et al. Cohort Profile: The Applied Research Group for Kids (TARGet Kids!). International Journal of Epidemiology. 2014. pii: dyu123. [Epub ahead of print]

25. de Onis M, Garza C, Victora CG. The WHO Multicentre Growth Reference Study: strategy for developing a new international growth reference. Forum of Nutrition. 2003; 56:238-240. 
26. Secker D. Promoting optimal monitoring of child growth in Canada: using the new WHO growth charts. Canadian Journal of Dietetic Practice and Research. 2010; 71:e1-3.

27. Fryar CD, Gu Q, Ogden CL. Anthropometric reference data for children and adults: United States, 2007-2010. National Center for Health Statistics. Vital Health Statistics. 2012; 11.

28. Expert panel on integrated guidelines for cardiovascular health and risk reduction in children and adolescents: summary report. Pediatrics. 2011; 128 Suppl 5:S213-256.

29. The fourth report on the diagnosis, evaluation, and treatment of high blood pressure in children and adolescents. Pediatrics. 2004; 114:555-576.

30. Corvalan C, Uauy R, Kain J, Martorell R. Obesity indicators and cardiometabolic status in 4-y-old children. American Journal of Clinical Nutrition. 2010; 91:166-174.

31. Messiah SE, Arheart KL, Natale RA, Hlaing WM, Lipshultz SE, Miller TL. BMI, waist circumference, and selected cardiovascular disease risk factors among preschool-age children. Obesity. 2012; 20:19421949.

32. Hanley AJ, Meigs JB, Williams K, Haffner SM, D'Agostino RB, Sr. Re: "(Mis)use of factor analysis in the study of insulin resistance syndrome". American Journal of Epidemiology. 2005; 161:1182-1184.

33. Meigs JB. Invited commentary: insulin resistance syndrome? Syndrome $X$ ? Multiple metabolic syndrome? A syndrome at all? Factor analysis reveals patterns in the fabric of correlated metabolic risk factors. American Journal of Epidemiology. 2000; 152:908-911; discussion 912.

34. Ashraf AP, Alvarez JA, Gower BA, Saenz KH, McCormick KL. Associations of serum 25hydroxyvitamin D and components of the metabolic syndrome in obese adolescent females. Obesity (Silver Spring). 2011; 19:2214-2221.

35. Steiner MJ, Skinner AC, Perrin EM. Fasting might not be necessary before lipid screening: a nationally representative cross-sectional study. Pediatrics. 2011; 128:463-470. 
Table 1. Descriptive characteristics of children with and without blood measures in TARGet Kids!

\begin{tabular}{|c|c|c|c|c|c|}
\hline \multirow[b]{2}{*}{ Variable } & \multicolumn{2}{|c|}{$\begin{array}{l}\text { Children with blood work } \\
\qquad(n=2917)\end{array}$} & \multicolumn{2}{|c|}{$\begin{array}{l}\text { Children without blood } \\
\text { work }(n=1774)\end{array}$} & \multirow[b]{2}{*}{ p-value } \\
\hline & $\begin{array}{c}\mathbf{N} \\
\text { missing }\end{array}$ & $\mathbf{N}(\%)$ & $\begin{array}{c}\mathrm{N} \\
\text { missing }\end{array}$ & $\mathbf{N}(\%)$ & \\
\hline Child Gender & & & & & 0.30 \\
\hline Male & 0 & $1545(53 \%)$ & 11 & 906 (51\%) & \\
\hline Female & & $1372(47 \%)$ & & 857 (49\%) & \\
\hline Maternal Education & 88 & & 90 & & 0.84 \\
\hline Post-secondary education ${ }^{1}$ & & $2538(90 \%)$ & & $1515(90 \%)$ & \\
\hline High school or less & & $291(10 \%)$ & & $169(10 \%)$ & \\
\hline Maternal Ethnicity & 0 & & 0 & & 0.08 \\
\hline European & & $1943(67 \%)$ & & $1228(69 \%)$ & \\
\hline East Asian & & $187(6 \%)$ & & $121(7 \%)$ & \\
\hline Southeast/South Asian & & $263(9 \%)$ & & $128(7 \%)$ & \\
\hline \multirow[t]{2}{*}{ Other } & & $524(18 \%)$ & & 297 (17\%) & \\
\hline & & Mean (SD) & & Mean (SD) & \\
\hline Age (years) ${ }^{2}$ & 0 & $2.91(1.51)$ & 98 & $2.62(1.53)$ & $<0.0001$ \\
\hline BMI z-score & 111 & $0.18(1.11)$ & 156 & $0.18(1.09)$ & 0.94 \\
\hline WC z-score & 152 & $-0.02(0.95)$ & 217 & $-0.03(1.03)$ & 0.64 \\
\hline Fasting duration (hours) & 425 & $1.86(1.23)$ & & & \\
\hline Non-HDL(mmol/L) & 86 & $2.80(0.68)$ & & N/A & \\
\hline $\mathrm{HDL}(\mathrm{mmol} / \mathrm{L})$ & 86 & $1.25(0.31)$ & & & \\
\hline $\mathrm{LDL}(\mathrm{mmol} / \mathrm{L})$ & 120 & $2.20(0.65)$ & & & \\
\hline Triglycerides (mmol/L) & 82 & $1.35(0.76)$ & & & \\
\hline Total cholesterol (mmol/L) & 69 & $4.04(0.70)$ & & & \\
\hline Apo-A (umol/L) & 1464 & $1.29(0.20)$ & & & \\
\hline Apo-B (umol/L) & 1462 & $0.67(0.16)$ & & & \\
\hline Glucose (mmol/L) & 66 & $4.63(0.67)$ & & & \\
\hline Insulin (pmol/L) & 128 & $61.49(55.38)$ & & & \\
\hline $25(\mathrm{OH}) \mathrm{D}(\mathrm{nmol} / \mathrm{L})$ & 177 & $84.79(30.01)$ & & & \\
\hline Adiponectin (ug/mL) & 1638 & $19.07(7.99)$ & & & \\
\hline ALT (units/L) & 65 & $18.97(10.83)$ & & & \\
\hline Leptin (ng/mL) & 1638 & $2.20(2.05)$ & & & \\
\hline $\mathrm{CRP}(\mathrm{mg} / \mathrm{L})$ & 136 & $1.51(4.98)$ & & & \\
\hline Systolic blood pressure ${ }^{3}(\mathrm{mmHg})$ & 1794 & $87.57(7.78)$ & & & \\
\hline Diastolic blood pressure (mmHg) & 1817 & $55.60(7.56)$ & & & \\
\hline
\end{tabular}

\footnotetext{
${ }^{1}$ Post-secondary education defined as CGEP/university/college/trade school

${ }^{2}$ Age at the time of first observation for each child. Among the subset of children $>3$ years of age, the mean age was 4.2 years $(S D=0.84)$.

${ }^{3}$ Blood pressure was measured only in children age 3 years and older $(N=2667)$ and interpreted for age, sex and height.
} 
Table 2: Odds ratio for the associations between both overweight or obese (BMI z-score $>1$ ) and obese only (BMI z-score $>2$ ) and traditional and possible non-traditional cardiometabolic factors in early childhood ( $\mathrm{n}=2912)$

\begin{tabular}{|c|c|c|c|c|}
\hline & & & $\begin{array}{l}\text { Overweight and Obese } \\
\text { (BMI z-score >1 vs. } \leq 1 \text { ) }\end{array}$ & $\begin{array}{c}\text { Obese (BMI z-score >2 } \\
\text { vs. } \leq 2 \text { ) }\end{array}$ \\
\hline Outcome Variables & $\begin{array}{l}\text { Cut points for } \\
\text { high risk }^{\mathrm{a}}\end{array}$ & $\underset{\text { missing }}{\mathbf{N}}$ & OR $(95 \% \mathrm{Cl})$ & OR $(95 \% \mathrm{Cl})$ \\
\hline Non-HDL cholesterol & $>3.11 \mathrm{mmol} / \mathrm{L}$ & 191 & $1.20(0.95,1.51)$ & $0.91(0.60,1.38)$ \\
\hline HDL cholesterol & $<1.17 \mathrm{mmol} / \mathrm{L}$ & 191 & $1.12(0.91,1.39)$ & $1.04(0.72,1.51)$ \\
\hline LDL cholesterol & $>2.85 \mathrm{mmol} / \mathrm{L}$ & 225 & $1.12(0.83,1.51)$ & $0.79(0.45,1.40)$ \\
\hline Triglycerides $^{\mathrm{b}}$ & $>0.84 \mathrm{mmol} / \mathrm{L}$ & 539 & $0.99(0.77,1.29)$ & $0.84(0.55,1.30)$ \\
\hline Total cholesterol & $>4.40 \mathrm{mmol} / \mathrm{L}$ & 178 & $1.00(0.80,1.27)$ & $0.77(0.51,1.17)$ \\
\hline Apo-A & $<1.2 \mathrm{~g} / \mathrm{L}$ & 1617 & $1.46(1.07,2.00)$ & $0.89(0.50,1.58)$ \\
\hline Apo-B & $>0.9 \mathrm{~g} / \mathrm{L}$ & 1617 & $0.80(0.43,1.49)$ & $0.43(0.10,1.78)$ \\
\hline Glucose ${ }^{b}$ & $>90^{\text {th }}$ percentile & 526 & $0.92(0.63,1.34)$ & $0.71(0.34,1.49)$ \\
\hline Insulin ${ }^{b}$ & $>90^{\text {th }}$ percentile & 582 & $0.88(0.61,1.28)$ & $1.76(1.05,2.94)$ \\
\hline $25(\mathrm{OH}) \mathrm{D}$ & $<75 \mathrm{nmol} / \mathrm{L}$ & 275 & $1.02(0.82,1.27)$ & $1.09(0.75,1.58)$ \\
\hline ALT & $>90^{\text {th }}$ percentile & 172 & $0.75(0.51,1.09)$ & $1.48(0.88,2.47)$ \\
\hline Leptin & $>90^{\text {th }}$ percentile & 1791 & $3.91(2.57,5.98)$ & $8.15(4.56,14.58)$ \\
\hline Adiponectin & $>90^{\text {th }}$ percentile & 1795 & $0.93(0.521 .64)$ & $1.81(0.83,3.96)$ \\
\hline CRP & $>90^{\text {th }}$ percentile & 247 & $0.94(0.66,1.35)$ & $0.98(0.53,1.81)$ \\
\hline Blood pressure ${ }^{c}$ diastolic & $>90^{\text {th }}$ percentile & 374 & $1.12(0.63,2.01)$ & $1.38(0.54,3.55)$ \\
\hline Blood Pressure systolic & $>90^{\text {th }}$ percentile & 351 & $1.97(0.69,5.66)$ & $N / A^{d}$ \\
\hline
\end{tabular}

${ }^{*} p<0.05$

\footnotetext{
${ }^{\text {a }}$ All outcome variables are dichotomized comparing the risk group to the reference category.

${ }^{\mathrm{b}}$ Adjusted for time since last meal

'Blood pressure was collected only on children age 3 years and older and interpreted for age, sex and height

${ }^{\mathrm{d} C}$ Cannot be calculated a cell count $=0$
} 
Table 3: Odds ratio for the associations between both waist circumference $z$-score $>1$ and waist circumference $z-$ score $>2$ and traditional and possible non-traditional cardiometabolic factors in early childhood $(n=2911)$

\begin{tabular}{|c|c|c|c|c|}
\hline & & & $\begin{array}{c}\text { WC } z \text {-score }>1 \text { vs. } \leq \\
1\end{array}$ & WC z-score $>2$ vs. $\leq 2$ \\
\hline & $\begin{array}{l}\text { Cut points for } \\
\text { high risk }^{\mathrm{a}}\end{array}$ & $\mathbf{N}$ missing & OR $(95 \% \mathrm{Cl})$ & OR $(95 \% \mathrm{Cl})$ \\
\hline Non-HDL cholesterol & $>3.11 \mathrm{mmol} / \mathrm{L}$ & 231 & $1.11(0.84,1.45)$ & $1.18(0.64,2.17)$ \\
\hline HDL cholesterol & $<1.17 \mathrm{mmol} / \mathrm{L}$ & 231 & $1.07(0.83,1.38)$ & $0.81(0.45,1.47)$ \\
\hline LDL cholesterol & $>2.85 \mathrm{mmol} / \mathrm{L}$ & 265 & $0.97(0.68,1.40)$ & $0.85(0.36,2.01)$ \\
\hline Triglycerides ${ }^{b}$ & $>0.84 \mathrm{mmol} / \mathrm{L}$ & 121 & $1.13(0.84,1.52)$ & $0.75(0.41,1.35)$ \\
\hline Total Cholesterol & $>4.40 \mathrm{mmol} / \mathrm{L}$ & 217 & $0.96(0.73,1.25)$ & $0.91(0.49,1.69)$ \\
\hline Apo-A & $<1.2 \mathrm{~g} / \mathrm{L}$ & 1634 & $1.03(0.70,1.52)$ & $1.10(0.45,2.73)$ \\
\hline Apo-B & $>0.9 \mathrm{~g} / \mathrm{L}$ & 1633 & $0.28(0.09,0.91)$ & \\
\hline Glucose $e^{b}$ & $>90^{\text {th }}$ percentile & 107 & $0.87(0.56,1.33)$ & $1.17(0.49,2.80)$ \\
\hline Insulin ${ }^{b}$ & $>90^{\text {th }}$ percentile & 164 & $1.59(1.11,2.28)$ & $2.48(1.29,4.79)$ \\
\hline $25(\mathrm{OH}) \mathrm{D}$ & $<75 \mathrm{nmol} / \mathrm{L}$ & 313 & $1.39(1.08,1.79)$ & $1.51(0.64,2.08)$ \\
\hline ALT & $>90^{\text {th }}$ percentile & 211 & $0.93(0.62,1.41)$ & $1.94(0.93,4.03)$ \\
\hline Leptin & $>90^{\text {th }}$ percentile & 1808 & $5.48(3.48,8.63)$ & $10.81(4.29,27.23)$ \\
\hline Adiponectin & $>90^{\text {th }}$ percentile & 1811 & $1.45(0.80,2.65)$ & \\
\hline CRP & $>90^{\text {th }}$ percentile & 286 & $1.01(0.67,1.53)$ & $1.53(0.68,3.44)$ \\
\hline Blood pressure ${ }^{c}$ diastolic & $>90^{\text {th }}$ percentile & 400 & $1.32(0.69,2.50)$ & $1.06(0.25,4.51)$ \\
\hline Blood Pressure systolic & $>90^{\text {th }}$ percentile & 378 & $0.43(0.06,3.24)$ & N/A \\
\hline
\end{tabular}

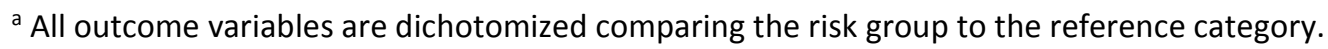

${ }^{\mathrm{b}}$ Adjusted for time since last meal

'Blood pressure was collected only on children age 3 years and older ( $\mathrm{N}=1641)$ and interpreted for age, sex and height 
Table 4: Principal components analysis for 5 traditional cardiometabolic risk factors

\begin{tabular}{|c|c|c|c|c|}
\hline \multicolumn{2}{|l|}{ All Children ( $N=2682)$} & \multicolumn{2}{|c|}{ Components } & \multirow[t]{2}{*}{ Communality } \\
\hline Item & Lipid & Metabolic & Adiposity & \\
\hline WC z-score & -0.03 & 0.01 & 1.0 & 1.0 \\
\hline $\mathrm{HDL}$ & 0.84 & 0.10 & -0.04 & 0.71 \\
\hline Glucose & -0.01 & 0.99 & 0.01 & 0.99 \\
\hline Triglycerides - log & -0.83 & 0.12 & 0.01 & 0.71 \\
\hline Variance Explained (\%) & 35.33 & 25.45 & 24.42 & \\
\hline Cumulative Variance (\%) & 35.33 & 60.78 & 85.20 & \\
\hline \multicolumn{5}{|l|}{ Age $\geq 3 \quad(n=1243)$} \\
\hline Item & Lipid & Adiposity/BP & Metabolic & \\
\hline WC z-score & -0.21 & 0.72 & -0.27 & 0.64 \\
\hline $\mathrm{HDL}$ & 0.82 & 0.04 & 0.08 & 0.67 \\
\hline Glucose & -0.06 & 0.01 & 0.92 & 0.85 \\
\hline BP - Systolic & 0.17 & 0.72 & 0.29 & 0.63 \\
\hline Triglycerides - log & -0.81 & 0.01 & 0.12 & 0.68 \\
\hline Variance Explained (\%) & 28.24 & 21.48 & 19.86 & \\
\hline Cumulative Variance (\%) & 28.24 & 49.71 & 69.58 & \\
\hline
\end{tabular}


Table 5. Principal components analysis including possible non-traditional cardiometabolic risk factor

\begin{tabular}{|c|c|c|c|c|c|c|c|c|}
\hline \multirow{2}{*}{$\begin{array}{l}\text { All ages ( } n=1006) \\
\text { Item }\end{array}$} & \multicolumn{7}{|c|}{ Components } & \multirow[t]{2}{*}{ Communality } \\
\hline & Lipid/HDL & $\begin{array}{c}\text { Lipid/ } \\
\text { non-HDL }\end{array}$ & Adiposity & Metabolic & $\begin{array}{l}\text { Adiponect } \\
\text { in/ALT }\end{array}$ & $\begin{array}{c}\text { ALT/ } \\
25(\mathrm{OH}) \mathrm{D}\end{array}$ & & \\
\hline Leptin- log & 0.14 & 0.23 & 0.67 & 0.20 & 0.18 & -0.04 & & 0.56 \\
\hline CRP- log & -0.46 & 0.02 & 0.01 & -0.06 & -0.20 & 0.07 & & 0.26 \\
\hline WC z-score & -0.07 & -0.06 & 0.83 & 0.05 & 0.02 & 0.00 & & 0.71 \\
\hline BMI z-score & -0.05 & -0.05 & 0.85 & 0.02 & -0.10 & -0.01 & & 0.74 \\
\hline ALT- log & -0.07 & -0.02 & 0.12 & -0.02 & 0.64 & 0.41 & & 0.59 \\
\hline Apo-A & 0.95 & 0.04 & 0.02 & -0.01 & -0.06 & -0.02 & & 0.91 \\
\hline Apo-B & -0.07 & 0.96 & -0.01 & -0.05 & 0.01 & 0.01 & & 0.93 \\
\hline Adiponectin- log & 0.04 & 0.06 & -0.02 & -0.04 & 0.80 & -0.19 & & 0.68 \\
\hline $25(\mathrm{OH}) \mathrm{D}$ & -0.05 & -0.02 & -0.07 & 0.01 & -0.03 & 0.91 & & 0.84 \\
\hline $\mathrm{HDL}$ & 0.91 & -0.11 & -0.03 & -0.06 & -0.17 & 0.03 & & 0.88 \\
\hline Non-HDL & -0.02 & 0.96 & 0.07 & 0.02 & 0.04 & -0.04 & & 0.94 \\
\hline Glucose & 0.03 & 0.05 & -0.04 & 0.83 & 0.00 & -0.09 & & 0.71 \\
\hline Insulin - log & -0.02 & -0.07 & 0.12 & 0.82 & -0.05 & 0.09 & & 0.70 \\
\hline $\begin{array}{l}\text { Variance } \\
\text { explained(\%) }\end{array}$ & 16.70 & 14.97 & 14.07 & 10.46 & 8.72 & 7.73 & & \\
\hline $\begin{array}{l}\text { Cumulative } \\
\text { variance(\%) }\end{array}$ & 16.70 & 31.67 & 45.74 & 56.21 & 64.93 & 72.66 & & \\
\hline \multicolumn{9}{|l|}{ Age $\geq 3 \quad(n=505)$} \\
\hline Item & Adiposity & Lipid/HDL & $\begin{array}{c}\text { Lipid/ } \\
\text { non-HDL }\end{array}$ & $\begin{array}{c}\text { Blood } \\
\text { Pressure }\end{array}$ & Metabolic & $\begin{array}{c}\text { ALT/ } \\
\text { 25(OH)D }\end{array}$ & $\begin{array}{c}\text { Inflammati } \\
\text { on }\end{array}$ & \\
\hline Leptin- log & 0.73 & 0.13 & 0.23 & 0.02 & 0.05 & 0.11 & 0.12 & 0.63 \\
\hline CRP- log & 0.08 & -0.32 & 0.02 & -0.02 & -0.04 & -0.04 & -0.45 & 0.31 \\
\hline WC z-score & 0.85 & -0.10 & -0.07 & 0.02 & 0.02 & -0.01 & -0.06 & 0.74 \\
\hline BMI z-score & 0.84 & -0.09 & -0.08 & 0.11 & -0.03 & -0.04 & -0.06 & 0.74 \\
\hline ALT - log & 0.17 & -0.12 & -0.08 & 0.00 & -0.13 & 0.77 & 0.17 & 0.56 \\
\hline Apo-A & -0.01 & 0.95 & 0.02 & 0.03 & 0.00 & -0.09 & 0.12 & 0.92 \\
\hline Apo-B & -0.02 & -0.05 & 0.95 & -0.06 & -0.05 & 0.01 & -0.05 & 0.92 \\
\hline Adiponectin- log & 0.05 & -0.07 & 0.03 & -0.05 & -0.01 & 0.00 & 0.89 & 0.81 \\
\hline $25(\mathrm{OH}) \mathrm{D}$ & -0.11 & -0.01 & 0.04 & -0.02 & 0.08 & 0.82 & -0.12 & 0.71 \\
\hline $\mathrm{HDL}$ & -0.04 & 0.94 & -0.10 & 0.00 & -0.03 & -0.06 & -0.03 & 0.90 \\
\hline Non-HDL & 0.05 & -0.04 & 0.96 & -0.05 & 0.00 & -0.05 & 0.07 & 0.93 \\
\hline Glucose & -0.03 & -0.01 & 0.04 & 0.03 & 0.81 & -0.14 & 0.05 & 0.69 \\
\hline Insulin - log & 0.07 & -0.01 & -0.09 & 0.03 & 0.82 & 0.11 & -0.03 & 0.70 \\
\hline BP - systolic & 0.02 & 0.00 & -0.04 & 0.87 & 0.08 & -0.08 & -0.04 & 0.78 \\
\hline BP - diastolic & 0.11 & 0.02 & -0.06 & 0.87 & -0.01 & 0.05 & 0.01 & 0.77 \\
\hline $\begin{array}{l}\text { Variance } \\
\text { Explained (\%) }\end{array}$ & 14.85 & 13.98 & 12.37 & 9.73 & 8.69 & 6.75 & 5.99 & \\
\hline $\begin{array}{l}\text { Cumulative } \\
\text { Variance(\%) }\end{array}$ & 14.85 & 28.83 & 41.20 & 50.93 & 59.63 & 67.35 & 74.09 & \\
\hline
\end{tabular}


Supplementary Figure 1. Flow chart of all children in the study.

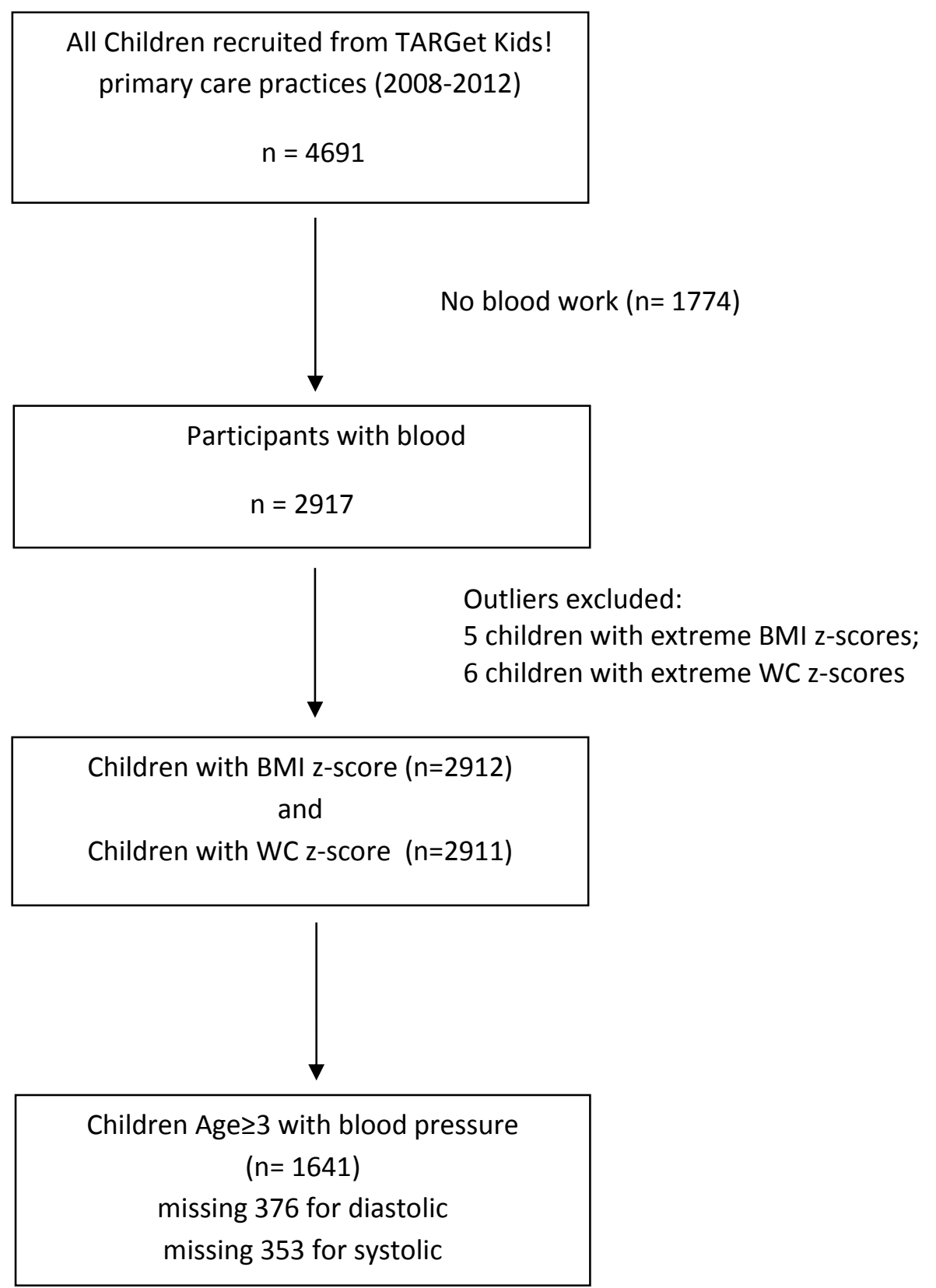


Supplementary Table 1. Principal components analysis for 8 traditional cardiometabolic risk factors

\begin{tabular}{|c|c|c|c|c|c|}
\hline \multirow{2}{*}{$\begin{array}{l}\text { All ages }(n=2598) \\
\text { Item }\end{array}$} & \multicolumn{4}{|c|}{ Components } & Communality \\
\hline & Adiposity & Metabolic & Lipid & & \\
\hline BMI z-score & 0.88 & 0.04 & 0.03 & & 0.77 \\
\hline WC z-score & 0.87 & 0.04 & -0.07 & & 0.77 \\
\hline Non-HDL & 0.04 & -0.04 & -0.76 & & 0.57 \\
\hline HDL & 0.01 & -0.03 & 0.77 & & 0.60 \\
\hline Insulin - log & 0.14 & 0.82 & 0.00 & & 0.70 \\
\hline Glucose & -0.05 & 0.84 & 0.01 & & 0.71 \\
\hline Variance Explained (\%) & 27.43 & 22.06 & 19.32 & & \\
\hline Cumulative Variance (\%) & 27.43 & 49.48 & 68.88 & & \\
\hline \multicolumn{6}{|l|}{ Age $\geq 3 \quad(n=1035)$} \\
\hline Item & Adiposity & $\begin{array}{c}\text { Blood } \\
\text { pressure }\end{array}$ & Metabolic & Lipid & \\
\hline BMI z-score & 0.88 & 0.06 & 0.01 & 0.04 & 0.78 \\
\hline WC z-score & 0.88 & 0.06 & 0.04 & 0.04 & 0.79 \\
\hline Non-HDL & 0.01 & -0.02 & -0.04 & 0.77 & 0.60 \\
\hline $\mathrm{HDL}$ & -0.06 & 0.05 & -0.06 & -0.73 & 0.55 \\
\hline Insulin - log & 0.09 & 0.06 & 0.83 & 0.01 & 0.70 \\
\hline Glucose & -0.04 & 0.01 & 0.83 & 0.01 & 0.70 \\
\hline BP - Systolic & 0.05 & 0.87 & 0.08 & -0.01 & 0.77 \\
\hline BP - Diastolic & 0.07 & 0.87 & -0.01 & -0.07 & 0.77 \\
\hline Variance Explained (\%) & 22.84 & 18.12 & 16.84 & 12.96 & \\
\hline Cumulative Variance (\%) & 22.84 & 40.95 & 57.79 & 70.76 & \\
\hline
\end{tabular}


Supplementary Table 2. Correlation matrix corresponding to the PCA with 4 traditional risk factors for all ages

\begin{tabular}{lrrrr}
\hline & zWC & HDL & Glucose & Triglycerides \\
\hline zWC & 1.00 & -0.06 & 0.02 & 0.05 \\
HDL & -0.06 & 1.00 & 0.02 & -0.40 \\
Glucose & 0.02 & 0.02 & 1.00 & 0.06 \\
Triglycerides & 0.05 & -0.40 & 0.06 & 1.00 \\
\hline
\end{tabular}

Supplementary Table 3. Correlation matrix corresponding to the PCA with 5 traditional risk factors, including blood pressure, for children age 3 and older

\begin{tabular}{lrrrrr}
\hline & zWC & HDL & Glucose & Triglycerides & SysBP \\
\hline zWC & 1.00 & -0.07 & 0.00 & 0.10 & 0.06 \\
HDL & -0.07 & 1.00 & 0.03 & -0.38 & 0.04 \\
Glucose & 0.00 & 0.03 & 1.00 & 0.06 & 0.06 \\
Triglycerides & 0.10 & -0.38 & 0.06 & 1.00 & 0.00 \\
SysBP & 0.06 & 0.04 & 0.06 & 0.00 & 1.00 \\
\hline
\end{tabular}


Supplementary Table 4. Correlation matrix corresponding to the PCA with 6 traditional risk factors for all ages

\begin{tabular}{lrrrrrr}
\hline & zBMI & \multicolumn{1}{c}{ zWC } & nonHDL & \multicolumn{1}{c}{ HDL } & Insulin & Glucose \\
\hline zBMI & 1.00 & 0.53 & 0.03 & 0.00 & 0.11 & 0.01 \\
zWC & 0.53 & 1.00 & 0.04 & -0.06 & 0.13 & 0.02 \\
nonHDL & 0.03 & 0.04 & 1.00 & -0.18 & -0.03 & 0.00 \\
HDL & 0.00 & -0.06 & -0.18 & 1.00 & -0.04 & 0.02 \\
Insulin & 0.11 & 0.13 & -0.03 & -0.04 & 1.00 & 0.41 \\
Glucose & 0.01 & 0.02 & 0.00 & 0.02 & 0.41 & 1.00 \\
\hline
\end{tabular}

Supplementary Table 5. Correlation matrix corresponding to the PCA with 8 traditional risk factors, including blood pressure, for children age 3 and older

\begin{tabular}{lccrrrrrr}
\hline & zBMI & \multicolumn{1}{c}{ zWC } & nonHDL & \multicolumn{1}{l}{ HDL } & Insulin & Glucose & \multicolumn{1}{c}{ SysBP } & DiasBP \\
\hline zBMI & 1.00 & 0.56 & 0.06 & -0.06 & 0.05 & 0.00 & 0.12 & 0.08 \\
zWC & 0.56 & 1.00 & 0.06 & -0.07 & 0.10 & 0.00 & 0.06 & 0.11 \\
nonHDL & 0.06 & 0.06 & 1.00 & -0.18 & -0.02 & 0.03 & -0.05 & -0.07 \\
HDL & -0.06 & -0.07 & -0.18 & 1.00 & -0.04 & 0.03 & 0.04 & 0.06 \\
Insulin & 0.05 & 0.10 & -0.02 & -0.04 & 1.00 & 0.40 & 0.08 & 0.04 \\
Glucose & 0.00 & 0.00 & 0.03 & 0.03 & 0.40 & 1.00 & 0.06 & 0.02 \\
SysBP & 0.12 & 0.06 & -0.05 & 0.04 & 0.08 & 0.06 & 1.00 & 0.52 \\
DiasBP & 0.08 & 0.11 & -0.07 & 0.06 & 0.04 & 0.02 & 0.52 & 1.00 \\
\hline
\end{tabular}


Supplementary Table 6. Correlation matrix corresponding to the PCA with 13 traditional and possible non-traditional risk factors for all ages

\begin{tabular}{lccccccccccccc}
\hline & Leptin & CRP & zWC & zBMI & ALT & ApoA & ApoB & Adip & VitD & HDL & $\begin{array}{c}\text { Non- } \\
\text { HDL }\end{array}$ & Glucose & Insulin \\
\hline Leptin & 1.00 & 0.00 & 0.36 & 0.39 & 0.08 & 0.11 & 0.14 & 0.10 & -0.05 & 0.00 & 0.21 & 0.01 & 0.08 \\
CRP & 0.00 & 1.00 & 0.02 & 0.05 & -0.08 & -0.25 & 0.06 & -0.01 & 0.09 & -0.18 & -0.03 & -0.02 & 0.02 \\
zWC & 0.36 & 0.02 & 1.00 & 0.53 & 0.08 & -0.05 & -0.02 & 0.01 & -0.05 & -0.06 & 0.04 & 0.02 & 0.13 \\
zBMI & 0.39 & 0.05 & 0.53 & 1.00 & 0.00 & -0.01 & -0.03 & -0.05 & 0.00 & 0.00 & 0.03 & 0.01 & 0.11 \\
ALT & 0.08 & -0.08 & 0.08 & 0.00 & 1.00 & -0.08 & 0.03 & 0.14 & 0.03 & -0.07 & -0.03 & -0.03 & -0.05 \\
Apo-A & 0.11 & -0.25 & -0.05 & -0.01 & -0.08 & 1.00 & -0.04 & 0.04 & -0.10 & 0.85 & 0.03 & 0.04 & -0.01 \\
Apo-B & 0.14 & 0.06 & -0.02 & -0.03 & 0.03 & -0.04 & 1.00 & 0.08 & -0.04 & -0.14 & 0.88 & -0.02 & -0.07 \\
Adip & 0.10 & -0.01 & 0.01 & -0.05 & 0.14 & 0.04 & 0.08 & 1.00 & -0.02 & -0.06 & 0.10 & 0.00 & -0.07 \\
VitD & -0.05 & 0.09 & -0.05 & 0.00 & 0.03 & -0.10 & -0.04 & -0.02 & 1.00 & -0.07 & -0.07 & -0.05 & 0.00 \\
HDL & 0.00 & -0.18 & -0.06 & 0.00 & -0.07 & 0.85 & -0.14 & -0.06 & -0.07 & 1.00 & -0.18 & 0.02 & -0.04 \\
nonHDL & 0.21 & -0.03 & 0.04 & 0.03 & -0.03 & 0.03 & 0.88 & 0.10 & -0.07 & -0.18 & 1.00 & 0.00 & -0.03 \\
Glucose & 0.01 & -0.02 & 0.02 & 0.01 & -0.03 & 0.04 & -0.02 & 0.00 & -0.05 & 0.02 & 0.00 & 1.00 & 0.41 \\
Insulin & 0.08 & 0.02 & 0.13 & 0.11 & -0.05 & -0.01 & -0.07 & -0.07 & 0.00 & -0.04 & -0.03 & 0.41 & 1.00 \\
\hline
\end{tabular}

Supplementary Table 7. Correlation matrix corresponding to the PCA with 15 traditional and possible non-traditional risk factors, including blood pressure, for children age 3 and older

\begin{tabular}{lllllllllllllllll}
\hline & $\begin{array}{c}\text { Lep- } \\
\text { tin }\end{array}$ & CRP & zWC & zBMI & ALT & $\begin{array}{c}\text { Apo- } \\
\text { A1 }\end{array}$ & ApoB & Adip & VitD & HDL & $\begin{array}{c}\text { Non- } \\
\text { HDL }\end{array}$ & $\begin{array}{c}\text { Gluc- } \\
\text { ose }\end{array}$ & $\begin{array}{c}\text { Ins- } \\
\text { ulin }\end{array}$ & $\begin{array}{c}\text { Sys- } \\
\text { BP }\end{array}$ & $\begin{array}{c}\text { Dias- } \\
\text { BP }\end{array}$ \\
\hline Leptin & 1.00 & 0.04 & 0.44 & 0.44 & 0.07 & 0.11 & 0.12 & 0.09 & -0.03 & 0.00 & 0.20 & -0.01 & 0.08 & 0.02 & 0.10 \\
CRP & 0.04 & 1.00 & 0.03 & 0.09 & -0.05 & -0.26 & 0.05 & -0.05 & 0.05 & -0.17 & -0.03 & -0.01 & 0.02 & 0.01 & 0.03 \\
zWC & 0.44 & 0.03 & 1.00 & 0.56 & 0.13 & -0.05 & 0.00 & -0.03 & -0.07 & -0.07 & 0.06 & 0.00 & 0.10 & 0.06 & 0.11 \\
zBMI & 0.44 & 0.09 & 0.56 & 1.00 & 0.11 & -0.02 & -0.03 & 0.00 & -0.04 & -0.06 & 0.06 & 0.00 & 0.05 & 0.12 & 0.08 \\
ALT & 0.07 & -0.05 & 0.13 & 0.11 & 1.00 & -0.06 & -0.05 & 0.04 & 0.08 & -0.02 & -0.05 & -0.07 & 0.00 & 0.01 & 0.01 \\
Apo-A & 0.11 & -0.26 & -0.05 & -0.02 & -0.06 & 1.00 & -0.02 & 0.09 & -0.09 & 0.84 & 0.03 & 0.00 & -0.02 & -0.02 & -0.01 \\
Apo-B & 0.12 & 0.05 & 0.00 & -0.03 & -0.05 & -0.02 & 1.00 & 0.03 & -0.05 & -0.10 & 0.87 & 0.03 & -0.04 & -0.06 & -0.04 \\
Adip & 0.09 & -0.05 & -0.03 & 0.00 & 0.04 & 0.09 & 0.03 & 1.00 & 0.02 & -0.01 & 0.09 & 0.01 & -0.03 & -0.06 & -0.03 \\
VitD & -0.03 & 0.05 & -0.07 & -0.04 & 0.08 & -0.09 & -0.05 & 0.02 & 1.00 & -0.08 & -0.04 & -0.06 & 0.01 & -0.05 & -0.04 \\
HDL & 0.00 & -0.17 & -0.07 & -0.06 & -0.02 & 0.84 & -0.10 & -0.01 & -0.08 & 1.00 & -0.18 & 0.03 & -0.04 & 0.04 & 0.06 \\
nonHDL & 0.20 & -0.03 & 0.06 & 0.06 & -0.05 & 0.03 & 0.87 & 0.09 & -0.04 & -0.18 & 1.00 & 0.03 & -0.02 & -0.05 & -0.07 \\
Glucose & -0.01 & -0.01 & 0.00 & 0.00 & -0.07 & 0.00 & 0.03 & 0.01 & -0.06 & 0.03 & 0.03 & 1.00 & 0.40 & 0.06 & 0.02 \\
Insulin & 0.08 & 0.02 & 0.10 & 0.05 & 0.00 & -0.02 & -0.04 & -0.03 & 0.01 & -0.04 & -0.02 & 0.40 & 1.00 & 0.08 & 0.04 \\
SysBP & 0.02 & 0.01 & 0.06 & 0.12 & 0.01 & -0.02 & -0.06 & -0.06 & -0.05 & 0.04 & -0.05 & 0.06 & 0.08 & 1.00 & 0.52 \\
DiasBP & 0.10 & 0.03 & 0.11 & 0.08 & 0.01 & -0.01 & -0.04 & -0.03 & -0.04 & 0.06 & -0.07 & 0.02 & 0.04 & 0.52 & 1.00 \\
\hline
\end{tabular}

